\title{
ÉTICA, COMUNICAÇÃO EM CONTEXTOS ORGANIZACIONAIS E A DEFESA DO CONSUMO CONSCIENTE
}

\author{
ETHICS, COMMUNICATION IN ORGANIZATIONAL CONTEXTS AND \\ CONSCIOUS CONSUMPTION'S DEFENSE
}

ÉTICA, COMUNICACIÓN EN CONTEXTOS ORGANIZACIONALES Y LA
DEFENSA DEL CONSUMO CONSCIENTE

Luiz Peres-Neto

Doutor, Escola Superior de Propaganda e Marketing

luiz.peres@espm.br

\section{Resumo}

Este artigo propõe uma reflexão acerca das construções discursivas enunciadas por organizações e consumidores acerca da noção de consumo consciente. Partimos do debate sobre ética, comunicação organizacional e consumo para analisar a polissemia que permeia as definições sobre o que seriam as práticas de consumo consciente. A partir deste quadro teórico realizamos um estudo empírico no qual analisamos discursos de quatro empresas e de 10 consumidores entrevistados. Além de sinalizar algumas das premissas éticas implicadas nos discursos sobre o consumo consciente, verificamos como estas se convertem em um importante valor para a comunicação organizacional enquanto se atribui aos sujeitos/consumidores a principal "responsabilidade moral" pelas práticas de consumo que melhoram o bem estar geral.

Palavras-Chave: Ética. Comunicação organizacional. Consumo consciente.

\begin{abstract}
This paper aims to analyze discursive constructions done by organizations and consumers on conscious consumption. Firstly, we point out some ethics landmarks, its relation with organizational communication and set the academic debate that relates it with consumption practices. Hence, we also review briefly the polysemy that founds the definitions on conscious consumption practices. Through this theoretical debate, we had realized an empirical study in which one discourses enunciated by four different companies and from 10 in deep interviews with consumers were analyzed as a way to highlight some ethical premises involved in the discursive construction of what would be conscious consumption practices and how it has become a value for organizational communication in which one moral responsibility concerns to consumers.
\end{abstract}

Keywords: Ethics. Organizational communication. Conscious consumption. 


\section{Resumen}

Este artículo propone una reflexión acerca de las construcciones discursivas enunciadas por organizaciones y consumidores acerca del consumo consciente. Inicialmente abordamos la noción de ética, su relación con la comunicación organizacional y con el campo del consumo, lo que nos permite revisar la polisemia de las definiciones sobre el consumo consciente. A partir de la susodicha arquitectura teórica realizamos un estudio empírico en el cual analizamos discursos de cuatro empresas y de 10 consumidores entrevistados. Con ello buscamos indicar algunas de las premisas éticas implicadas en la construcción discursiva de lo que serían las prácticas de consumo consciente y de cómo éstas se convierten en un valor ético para la comunicación de las organizaciones en la que la responsabilidad moral se atribuye a los sujetos-consumidores.

Palabras clave: Ética. Comunicación organizacional. Consumo consciente.

\section{INTRODUÇÃO}

As reflexões sobre ética e comunicação organizacional, salvo raras exceções como alguns artigos do "Dossiê" sobre esta temática da revista Organicom (2008) ${ }^{1}$ usualmente operam análises deontológicas a partir do estudo de códigos de conduta empresarial ou do Código de Ética do Profissional de Relações Públicas (BARROS FILHO, 2007). Com efeito, poucas são as contribuições que problematizam acerca da complexidade dos valores morais que circulam em determinados espaços sociais, tais como empresas, governos ou instituições, transcendentes não só para a coesão de uma sociedade como também para a legitimação de condutas (idem, ib.).

Nesse sentido entendemos ser importante sugerir uma discussão sobre ética e comunicação organizacional distante dos mencionados códigos, que colabore para que, paulatinamente, ética e comunicação organizacional sejam pensadas também a partir de outras perspectivas, que não apenas a deontológica. Neste artigo propomos abordar a temática da ética na comunicação em contextos organizacionais a partir da sua interface com o campo do consumo.

Como destacam Rocha e Casaqui (2012), as pesquisas acerca das interfaces entre comunicação e consumo ganharam um inegável espaço no campo acadêmico brasileiro na última década. Diversos autores vêm abordando problemáticas de grande interesse, também para a pesquisa em comunicação organizacional. Sendo assim, como objeto de

\footnotetext{
${ }^{1}$ Dos seis artigos que compõe o Dossiê "Ética e comunicação organizacional" da revista Organicon (2008), apenas um abordava a questão da ética empresarial como sinônimo da discussão sobre a evolução dos Códigos de conduta empresarial.
} 
estudo, especificamente, propomos investigar as dimensões éticas das práticas discursivas, tanto de organizações como também de consumidores, acerca da noção de "consumo consciente", um conceito que implicitamente maneja concepções de ética inerentes às organizações e aos consumidores (SILVA e colaboradores, 2012).

Para investigar tal objeto, realizamos não só uma reflexão teórica como também um estudo empírico. Desse modo, o presente artigo foi articulado em quatro partes. Em um primeiro momento, discutimos dois paradigmas éticos que norteiam grande parte do debate sobre ética e organizações (ENRIQUEZ, 1997) e são balizadores das análises que realizaremos. São eles: a "ética da convicção", modelo arquitetado fundamentalmente ao auspício das teses de Immanuel Kant (2002), que vindica a justificação moral das ações humanas nelas mesmas e a "ética da responsabilidade", paradigma edificado sobre todo a partir das propostas de Max Weber (2009; 2011), que explica a necessidade do ser humano postular uma ética da alteridade. Desse modo, na primeira parte deste trabalho revisaremos estas duas propostas a fim de problematizar a ética nas organizações.

Interessa-nos, em especial, situar as dimensões comunicacionais da ética nas organizações a partir da reflexão sobre a ação humana, ou seja, sob a égide da filosofia moral. Isso porque ao indagarmos acerca da moral nos contextos organizacionais abrimos uma via para pensar o consumo. Com efeito, em um segundo momento, revisaremos a dimensão moral atinente à noção de consumo e as diversas teorizações que procuram explicar o fenômeno do "consumo consciente". Como defende Miller (2007), toda prática de consumo se insere em uma lógica cultural de atribuição de valor às formas simbólicas o que, com outras palavras, abre-nos o caminho para discutir ética, consumo e comunicação. $\mathrm{O}$ ato de atribuir valor reserva uma clara dimensão comunicativa acerca dos valores compartilhados e consagrados como bons. Buscaremos, desse modo, relacionar a dimensão moral das práticas de consumo com as suas interfaces comunicacionais, em especial, com o campo da comunicação organizacional.

Posto isso, em um terceiro momento, apresentaremos o estudo empírico realizado. Por um lado, analisamos discursos sobre consumo consciente enunciados por quatro empresas fundadoras do Instituto Akatu, instituição que pioneiramente introduziu a discussão sobre consumo consciente no Brasil. Trata-se, por tanto, de organizações vanguardistas na construção de uma agenda empresarial sobre este tema. Por outro lado, analisamos 10 entrevistas em profundidade realizadas com consumidores, nas quais 
pudemos indagar-lhes tanto sobre o conceito de consumo consciente quanto acerca da percepção dos mesmos sobre a comunicação dos valores institucionais das quatro empresas estudadas no tocante às práticas de consumo consciente. Como procedimento de análise, trabalhamos com a perspectiva dos Estudos Críticos do Discurso.

Em um quarto e último momento, por fim, apontamos alguns desafios éticos inerentes à relação sujeitos/ organizações derivados da comunicação das práticas de consumo consciente. Mais do que encontrar respostas ou certezas definitivas, propomos uma reflexão sobre a égide da complexidade dos valores morais em circulação, o que nos requer um duplo movimento teórico-metodológico ao analisar a questão do consumo consciente, que nos permita entender as dimensões éticas dessa prática sem obviar as mediações comunicacionais entre organizações e consumidores.

\section{2 ÉTICA E COMUNICAÇÃO ORGANIZACIONAL: UM PONTO DE PARTIDA}

O incremento da preocupação pela ética no universo organizacional, segundo Lovison e Petroll (2011), ganha um inegável fôlego, primeiramente no contexto norteamericano e, posteriormente, na Europa e demais países, a finais dos anos 50 do século passado. Para os mencionados autores, "apesar de este movimento ter adquirido força a partir de alguns escândalos de corrupção (por exemplo, Watergate, Lockheed e Gulf Oil), a ética não se reduz à correção de fenômenos deste tipo" (LOVISON; PETROLL, 2011, p.335).

Com efeito, a ética alude à conduta humana. Pressupõe refletir moralmente sobre todas as ações do homem, não apenas sobre àquelas consideradas socialmente repugnantes (VALLS, 2012). Moral que deve ser entendida como o processo individual e livre de atribuição de valor ao agir (BARROS FILHO; MEUCCI, 2010). Desse modo, o sentido da moral não pode ser confundido com o ato de castigar ou condenar o agir do homem; pensar sobre a moral é refletir sobre as virtudes das ações (SPONVILLE, 2002). Pensar moralmente supõe refletir sobre os "valores concernentes ao bem e ao mal, ao permitido e ao proibido e à conduta correta e incorreta, válidos para todos" (CHAUÍ, 2012, p.386).

Por essa razão, amiúde se confunde ética, moral e o universo das leis. Pensar moralmente é refletir sobre a virtude de uma ação, o que fazemos a partir de modelos éticos, ou seja, em base a acordos estabelecidos dentro de uma sociedade. No entanto, para Chauí (2012, p.396) "a simples existência da moral não significa a presença 
explícita de uma ética”. Ainda que ética e moral possuam a mesma genealogia (RICOEUR, 2011), entendemos que são conceitos que podem ser abordados separadamente (RIOS, 2008). Ainda que a moral seja fundamento para a construção de modelos éticos, estes são pactos estabelecidos entre indivíduos que permitem uma harmonização dos valores em circulação em certos contextos socioculturais. A moral, além de um marcado caráter de reflexão individual sobre a conduta humana, requer inexoravelmente o livre agir dos sujeitos (SPONVILLE, 2002). A ética, por sua vez, é uma espécie de ciência da moral (CORTINA, 2010). Em outras palavras, a ética reúne acordos que se constroem a partir de pautas morais forjadas dentro de uma determinada cultura.

Desse modo, cabe a alocação de padrões éticos em relação a espaços ou grupos socioculturais determinados. Podemos, assim, inferir que as organizações constroem e estabelecem conjuntos de valores que são aplaudidos ou condenados moralmente no contexto cultural das mesmas. Uma empresa como a Nestlé, por exemplo, consagrará determinados valores - não só aqueles explicitados no seu perfil institucional - como sendo os que fundamentam a sua ética enquanto outra organização, como o banco Itaú, forjará valores similares e/ou outros. A ética das organizações requer, nesse sentido, um conhecimento da cultura organizacional. Contudo, os valores morais arquitetados por uma determinada classe, grupo ou simplesmente aceitos em certos espaços sociais não aniquila a existência de outros valores, alternativos, difusos ou minoritários, razão pela qual o filósofo francês Edgar Morin (2005) explica a complexidade inerente aos valores morais em circulação.

Como recorda Marina (2011) a ética sinaliza possíveis caminhos para que a existência possa ser virtuosa, mas não garante que a mera adoção dos mesmos afiance uma vida boa. Isso porque a ética convida os indivíduos a problematizarem os significados dos valores morais. Esses tendem a ser naturalizados pela sociedade, uma vez que são anteriores aos indivíduos e dão forma aos costumes (CHAUÍ, 2012, p.386). Ao tencioná-los, descortina-se a possibilidade de agir eticamente e não apenas em função de padrões ou leis de conduta. Por essa razão, para Arendt (2004), quando um indivíduo, ante uma situação controversa, é capaz de dizer "não devo" em lugar de "não posso" ou "não quero", efetivamente tem-se uma ação ética. Dizer "não posso" pressupõe o veto de alguma lei ou norma enquanto "não quero" se resume à arbitrariedade dos desejos. Não obstante, "não devo" delata a existência de uma consciência moral e o caráter de pessoas que são capazes de privilegiar uma escolha 
ética a uma escolha meramente baseada nos limites das leis ou nos apetites dos desejos circunstanciais.

Por essa razão entendemos que se esvazia a possibilidade de entender os códigos de ética como um espaço para a discussão da ética em si. De fato, esses deveriam chamar-se códigos deontológicos. Enquanto a ética se preocupa com a reflexão moral da ação humana, esses catálogos prescrevem uma série de condutas esperadas ou desejadas. Não problematizam valores morais e colaboram para a naturalização de certos axiomas como sinônimos do justo, do adequado, do bem ou do mal. Reduzem a complexidade dos mesmos a prescrições comportamentais.

Como bem destaca Camps (2012), entretanto, a crescente preocupação pela ética empresarial, contraditoriamente, tem catapultado uma verdadeira proliferação de tais códigos nas organizações, públicas e privadas. Ao editar um código de ética, muitas organizações esperam sepultar os dilemas e conflitos éticos. Para Lovison e Petroll (2011, p.337), “quando uma empresa oferece aos seus funcionários e clientes um código de ética interno, o efeito nem sempre é o de orientar eticamente as suas práticas, mas dar uma garantia de que as suas atividades são eticamente irreprocháveis".

Privilegia-se a imagem empresarial à discussão de valores morais complexos, muitas vezes embaraçosos. Como a ética representa um terreno tortuoso, susceptível às sensibilidades, contemporaneamente, as organizações passaram a depositar ainda mais atenção a ela (CAMPS 2012; SROUR, 2000; ENRIQUEZ, 1997). Paradoxalmente, ao abandeirar a catalogação da ética, consciente ou inconscientemente, as organizações anulam a mesma, convertendo-a em um dado objetivável e, consequentemente, quantificável. Para Enriquez (1997, p.8), “a empresa (mesmo que ela empreste a noção de performance do mundo esportivo) tenta impor sua visão tecnicista do futuro humano". Embora busquem, em suma, comunicar à sociedade os seus valores, ao se instalarem no terreno da ética codificável, as organizações - orientadas por princípios contábeis do capitalismo - tendem a privilegiar a racionalidade instrumental em detrimento das contradições das ações humanas, aprisionando a ética em mais um item passível de aferição da performance organizacional e também dos indivíduos.

É nesse contexto que emergem expressões como "empresa cidadã", que buscam dar um conforto a funcionários, consumidores e demais públicos de interesse de uma organização. Valores e direitos reservados à esfera individual como a cidadania, entre outros, passam a compor o repertório dos discursos organizacionais que buscam, desse modo, construir um novo homem, capaz de ser "gestor" de si mesmo. A própria noção 
de gestor revela o trinfo da funcionalidade sobre a angústia própria das paixões e contradições da alma humana. Muitas organizações situam seus "colaboradores" como o seu "capital mais precioso", ignorando que a equiparação dos sujeitos à categoria de capital reduz os mesmos a meros recursos econômicos e, como tal, estocáveis, maleáveis; em suma, passíveis de uma administração. Como destaca Freire Filho (2011, p.40) "o culto da performance aponta para um devir atlético e empresarial da sociedade, um processo de conversão aos valores supremos da concorrência e da conquista".

O culto dos valores de excelência individual e organizacional simboliza a racionalidade instrumental levada ao seu expoente máximo. Com isso, o discurso organizacional sobre ética passa a ser frequentemente o discurso objetivo dessa racionalidade. É preciso recordar, no entanto, que as organizações, como mobilizadoras de sentidos, ao buscarem ser éticas, tendem a impor padrões morais à sociedade, tendo os seus funcionários como porta-vozes cotidianos. Com isso, tanto organizações como indivíduos buscam continuamente legitimar certos valores morais, razão pela qual entendemos que os discursos organizacionais representam um espaço primoroso para a análise e estudo da ética. Tradicionalmente, dois paradigmas éticos servem de marco para essas análises: a ética da convicção, baseada na filosofia moral kantiana e a ética da responsabilidade, impulsada por Max Weber (2011).

O filósofo alemão Immanuel Kant engendrou fundamentalmente nas obras “Crítica da razão pura”, publicada em 1788, e "Fundamentação da metafísica dos costumes", de 1785, uma proposta de filosofia moral que, posteriormente, veio a ser conhecida como ética da convicção. Agir por convicção pressupõe a racionalidade dos indivíduos. Kant (2004) analisa, na primeira parte da sua "Crítica da razão pura", as circunstancias em que a razão opera, como se dá o seu funcionamento e a finalidade da mesma para embasar o agir do homem no mundo.

Para Kant (2004), como seres racionais e livres, podemos submeter as nossas ações ao exame de uma "lei moral", emanada esta da razão prática. Somente pela razão podemos acessar a realidade e, portanto, conhecer o bem e o mal. Em suas palavras, "só uma lei formal, isto é, uma lei que não prescreva à razão nada mais do que a forma de sua legislação universal, como suprema condição das máximas, pode ser a priori um fundamento de determinação da razão prática" (KANT, 2004, p. 131). Desse modo, Kant defende a necessidade de um "imperativo categórico", que permita a universalização das condutas moralmente validas. $\mathrm{O}$ exame da razão fundamenta que a 
ação do homem se dê a partir de uma regra: que a minha ação possa ser parâmetro universal para outras ações similares.

Após ter despojado a vontade de todos os impulsos capazes de nela serem suscitados pela idéia dos resultados provenientes da observância de uma lei, nada mais resta do que a conformidade universal das ações a uma lei em geral que deva servir-lhe de princípio: noutros termos, devo portar-me sempre de modo que eu possa também querer que minha máxima se torne em lei universal. (KANT, 2002, p. 31)

Não há, no modelo kantiano, espaço para dúvidas. Trata-se, como bem destaca Enriquez (1997, p. 14) de "uma ética do tudo ou nada", posto que "uma convicção não se negocia”. Segundo esta ética, uma ação moralmente válida é aquela que pode ser universalizada. Seria fazer, como explica Marcondes (2009, p.87) “cumprir o que prometemos e manter nossa palavra porque esperamos que as outras pessoas também o façam, e se não fizerem, toda a prática de fazer promessas desmorona". Agir moralmente dentro da ética da convicção, portanto, supõe impor aos sujeitos, racionalmente, a consciência de um finalismo moral que deve ser alcançado a qualquer custo.

Embora a formulação desse paradigma tenha sido arquitetada por Kant, foi o sociólogo alemão Max Weber (2011) que a nomeou como "ética da convicção", em um esforço para distingui-la da "ética da responsabilidade", proposta, esta sim, construída por Weber. Agir por responsabilidade requer outra maneira de emoldurar os fundamentos da moral. No caso da responsabilidade, o parâmetro e a questão do dever ser ético estão não mais na convicção de quem age e sim na alteridade. A avaliação das possibilidades de ação apela não para leis ou empecilhos categóricos, mas sim às consequências dos nossos atos. Agir por responsabilidade requer meditar sobre as consequências dos mesmos para com os outros. Só se é responsável para com alguém.

Weber (2011) ressalta que é na politica onde encontramos um espaço para o exercício da ética da responsabilidade. Segundo o seu entender, um líder político deve agir não segundo as suas próprias crenças, apetites ou certezas. Este deve pautar as suas ações segundo a sua responsabilidade para com os que sofrem os efeitos de suas decisões. Esta proposta, como explica Marcondes (2009, p.122), "valoriza sobretudo as consequências da ação e a relação entre meios e fins, com base nas quais um ato deve 
ser julgado como bom ou mau". Trata-se, em definitiva, de aceitar a possibilidade de que existem valores éticos contraditórios e oferecer um caminho para que sempre prevaleçam aqueles valores cujos resultados sejam benéficos para com os demais.

Assumir responsabilidades nos convida a deliberar moralmente de uma maneira não dogmática. Em contextos organizacionais, supõe equilibrar as responsabilidades para com uma determinada organização ante a responsabilidade para com os outros. Com efeito, defende Enriquez (1997, p. 15) que, "o problema é bem mais sério em nossos dias, já que as organizações são mais complexas e formulam exigências variadas a seus colaboradores". O cotidiano daqueles que têm responsabilidades é, em suma, um contínuo arbítrio ante o tribunal da moral.

Evidentemente a formulação de paradigmas éticos não se limita a esses dois modelos resenhados. A atribuição de um valor moral a uma ação humana reveste a escolha de uma possibilidade entre infinitas outras. Consequentemente, podem ser arquitetados inúmeros modelos e classificações éticas (CORTINA, 2010). Contudo, as duas propostas descritas anteriormente abarcam possibilidades teórico-metodológicas que vem ao encontro das nossas necessidades, de estudar as dimensões éticas das práticas discursivas, tanto de organizações como também de consumidores, acerca da noção de "consumo consciente".

\section{COMUNICAÇÃO ORGANIZACIONAL E A POLISSEMIA DO TERMO CONSUMO CONSCIENTE}

Diversos autores situam as noções de consumo conspícuo e consumo vicário, teorizadas por Veblen (2004), na primeira metade do século XX, como a origem para a construção do termo consumo consciente (ROUX, NANTEL, 2010; SZMIGIN, CARRIGAN, McEACHERN, 2009). A inquietude das empresas em oferecer à sociedade uma proposta que explicitamente vincule à dimensão material das práticas de consumo uma virtude moral, higienizando a visão - que remonta a antiguidade clássica de que o consumo coroe o caráter do homem (CAMPBELL, 2008), auxilia, no nosso entender, a reprodução desse termo nas agendas contemporâneas das organizações.

Sem lugar a dúvidas consumir é uma das atividades mais básicas realizadas pelos seres humanos. Pode-se "viver sem produzir, mas, não sem consumir" (BARBOSA, 2006 , p.7). Contudo, enquanto a produção se relaciona com a capacidade virtuosa do homem de agir no mundo, de construir e obrar criativamente, como argumenta Miller (2007), ao consumo, frequentemente, se atribui um padrão moral pouco virtuoso, de 
destruição, de eliminação das materialidades. Trata-se de um dos processos que colaboram para atrelar uma dimensão moralista ao consumo, segundo a qual o mesmo deve estar limitado às necessidades, o que gera um "padrão moral de necessidade" (idem, p.35).

É interessante destacar que se estabelece uma relação divergente entre a esfera da produção (trabalho) e o âmbito do consumo em sua dimensão moral. Segundo Barbosa e Campbell (2006), ao consumo se costuma atribuir um valor pejorativo enquanto o trabalho se reserva um âmbito para a redenção moral do ser humano. Neste contexto, os citados autores relembram a própria definição do termo consumo. Este pode significar tanto exaurir, esgotar, destruir - quando relacionado ao termo latino consumere - ou pode indicar somatória, consumação, quando derivado do termo inglês consumption. Destacam, contudo, que no Brasil a cotação está mais próxima de um valor negativo.

Neste contexto, a comunicação organizacional relegou ao marketing - e a áreas conexas a este - a comunicação de valores relacionados ao consumo. Entretanto, a emersão das preocupações com as chamadas práticas sustentáveis re-situaram a necessidade de introduzir, na comunicação organizacional, valores atrelados ao consumo. Para Alípio Casali (2008, p.56) "o fenômeno é novo: o consumo controla cada vez mais a produção. A força da consciência dos consumidores tem sido reconhecida como elemento decisivo no jogo competitivo do mercado".

A preocupação com os valores atrelados ao consumo passou a ser uma inquietude da comunicação organizacional, seguindo Casali (2008), apenas por uma inversão na equação mercantil produção-consumo. Não obstante, cabe matizar alguns aspectos. Não se trata de um fenômeno novo se abordado pela lógica da concorrência, competição ou mercado. Como observa Alonso (2006), os estudos do consumo estiveram durante muitos anos conduzidos predominantemente pelas ciências econômicas. Considerando que esta área do saber postula teses muito mais centradas nas análises das estratégias de demanda e produção, as práticas de consumo sempre foram, desde este ângulo, analisadas como um processo equacional, o que, em consequência, amaina o estudo do consumo como fenômeno genuinamente social.

Supor que os consumidores controlam cada vez mais a produção requer partilhar de um idealismo ingênuo, que ignore as relações assimétricas de poder econômico entre organizações e consumidores. Ao aceitar este postulado estaríamos compactuando com uma visão centrada no individualismo econômico das práticas de consumo. Esta posição é duramente criticada por Alonso (2006), para quem a visão microeconômica fomentou 
um individualismo metodológico sobre as práticas de consumo. Destaca-se, predominantemente, duas consequências deste processo: o estudo do homem como consumidor, movido em função de necessidades racionais e a delimitação da vida social em um espaço de relações muito particular, o mercado.

Indubitavelmente há uma "racionalidade econômica" no bojo de qualquer definição sobre consumo posto que o mesmo é parte de um ciclo de produção e reprodução social (CANCLINI, 2008). Entretanto, faz-se necessário entender o consumo como "o conjunto de processos socioculturais em que se realizam a apropriação e os usos dos produtos" (idem, p.61). Assim, como recorda Taschner (1997), o consumo passa a ser objeto de estudo a partir da sua relação com a cultura. A análise das práticas de consumo pressupõe a inscrição do mesmo "no campo mais amplo da crítica da cultura" (ROCHA, 2012, p.24).

Toda prática de consumo é, desse modo, simbólica. No entanto, Miller (2007) recorda que se deve privilegiar uma abordagem do consumo na sua dimensão cultural sem obviar a sua relação com o universo das materialidades. Entende o mencionado autor que, assim, é possível resgatar a cultura material do consumo, extraindo da mesma a moralidade subjacente de que "indivíduos puros ou relações sociais puras são contaminadas pela cultura de mercadorias" (MILLER, 2007, p. 38).

O senso comum conduz - erroneamente - à construção de imagens de que existem relações sociais "puras" ou, por seguir a proposta de Miller (2007), fundadas em um anti-materialismo. Com isso, os bens de consumo supostamente entorpeceriam as relações sociais. As organizações, seguindo esta lógica, colaborariam para o enfraquecimento dos laços sociais entre os indivíduos. Cabe recordar, no entanto, a proposta de Douglas e Isherwood (2004), que defendem criticamente a tese de que os bens de consumo constituem um sistema de comunicação similar à linguagem. A comunicação organizacional supostamente deveria contribuir para a tradução desses signos à sociedade o que, ao contrário dos postulados anti-materialistas, colaboraria para a vinculação do consumo como um processo sócio-cultural de partilha de sentidos, de atribuição de valor ao mundo e de reflexão sobre a própria conduta humana, ou seja, um locus para a discussão da ética.

É interessante situar, nesse contexto, a própria construção da definição do termo consumo consciente. Trata-se de um conceito polissêmico, ao qual Roux e Nantel (2010) destacam duas linhas mais proeminentes. De um lado, usualmente se emprega o termo consumo consciente para designar práticas de consumo material responsáveis 
para com o meio ambiente e, de outro, se relaciona este conceito a uma visão crítica ao consumo conspícuo. Este dualismo gera um movimento pendular onde ora prevalecem questões ambientais, ora econômicas, porém sempre permeadas por uma visão moral das práticas de consumo, ou seja, de atribuição de um valor às mesmas.

Um dos autores clássicos do pensamento organizacional, Etizioni (1998, p.620), por exemplo, defende que o consumo consciente é aquele que limita os gastos com bens e serviços. Já autores behavioristas, como Szmingin et al (2009, p.225), por sua vez, defendem que o consumo consciente é aquele que propicia escolhas éticas ao consumidor, ou seja, que é capaz de alterar o seu comportamento no ato de suas compras. Outros autores, como Connell (2009), por exemplo, entendem que o consumo consciente é aquele que serve à causa ambiental a partir da sensibilização dos consumidores para com questões ecológicas e meio-ambientais.

Ainda que o termo consumo consciente não tenha uma definição uníssona, a partir da literatura consultada, poderíamos afirmar que o mesmo seria um contraponto ético ao "consumismo" - entendido como a aquisição desmesurada de bens ou serviços a despeito da satisfação das necessidades dos indivíduos - ou como uma prática restritiva a certos produtos, serviços ou empresas em prol da causa ambiental. Tais visões, no entanto, pressupõem uma acepção do consumo atrelado à racionalidade do homo oeconomicus em detrimento do entendimento deste como uma prática sociocultural.

Cabe destacar que são escassas as definições gestadas desde o campo da comunicação para a discussão do consumo consciente, seja pela ausência de autores ou pelas propostas que limitam o papel da comunicação como mero instrumento informativo, capaz de auxiliar os indivíduos nos seus atos de compra, através da publicidade ou das informações contidas nas embalagens de certos produtos. O papel das organizações, e da comunicação organizacional é também pouco analisado. Emergem, por sua vez, desde a sociologia, vozes críticas como a de Silva, Araújo e Santos (2012), para quem as organizações, inseridas na engrenagem capitalista, utilizam as causas ambientais como um meio para fomentar o incremento do consumo, tendo a comunicação como mecanismo alienador das massas.

No contexto brasileiro, contudo, o debate sobre o consumo consciente ganha contornos particulares posto que a referência para a teorização do mesmo se deu pelo e desde o mercado. Barros e colaboradores (2010) destacam o papel do Instituto Akatu e os esforços do mesmo para construir um conceito fechado acerca do termo consumo 
consciente, que respondesse aos anseios do mercado. De tal sorte, a visão postulada pelo Akatu não permitiu a discussão sobre os pressupostos ontológicos implicados na mesma. Dado o caráter vanguardista e a credencial "não governamental" do Akatu, tal teorização paulatinamente se impôs como inequívoca. Não obstante, o instituto Akatu, por mais autônomo que seja é, em síntese, uma ONG criada pelo e para o mercado.

Para Barros e colaboradores (2010, p.757-758), o Akatu disseminou a visão de consumo consciente desejada e forjada pelas empresas que o criaram, razão pela qual se priorizou um debate ético, centrado na responsabilidade individual dos consumidores, sem defender uma redução do consumo material, como postula parte da literatura supracitada. Assim, se mantêm os interesses dos apoiadores institucionais.

Para o Akatu (2013), “consumo consciente é consumir diferente”. Decorre de um processo no qual o consumidor deve assumir a sua condição de ser racional, arbitrar e optar, avaliando as possibilidades, por um consumo mais "sustentável” e ético. Seja como for, sustenta-se a contraposição de um consumo bom, responsável, em detrimento de outro, ruim e indesejado. Buscaremos indagar a vigência e validade deste postulado ético a partir do estudo tanto dos discursos das organizações fundadoras do Akatu como também da análise de discursos articulados por consumidores.

\section{ESTUDO EMPÍRICO}

Conforme argumentamos, propomos investigar as dimensões éticas das práticas discursivas, tanto de organizações como também de consumidores, acerca da noção de consumo consciente. Sendo assim, construímos uma amostra com dois conjuntos de textos: de um lado, um corpus com discursos organizacionais e, de outro, discursos de consumidores coletados em entrevistas em profundidade realizadas para tal fim.

No tocante às organizações, selecionamos discursos sobre o consumo consciente, enunciados por quatro das empresas fundadoras do Instituto Akatu, instituição que pioneiramente introduziu a discussão sobre consumo consciente no Brasil. Trata-se, por tanto, de organizações vanguardistas na construção de uma agenda empresarial sobre este tema. São elas: Nestlé, Hewlett Packard (HP), Itaú e Santander. Coletamos para a análise as peças discursivas disponíveis nas páginas de internet das mencionadas empresas, sobre os valores institucionais. Entendemos que se trata de uma opção qualitativa e que se justifica na medida que são estes os textos que um consumidor comum terá acesso quando busque informações sobre essas empresas. Cabe matizar, 
contudo, que conformamos uma amostra irregular, posto que cada uma das organizações estudadas disponibiliza uma quantidade de texto com volume diferente. No entanto, como bem destaca Maldonado (2006, p.278) "o empírico em termos metodológicos compreende o conhecimento adquirido pela prática, o conhecimento sensível baseado na experiência, o conhecimento factual que foi experimentado e não necessariamente uma observação controlada".

Por sua vez, realizamos também 10 entrevistas em profundidade com consumidores. Essa amostra também foi construída qualitativamente e, em consequência, não é representativa e não faz parte de "uma observação controlada". Construímos a mesma seguindo critérios qualitativos. Buscamos consumidores com formação universitária, 5 homens e 5 mulheres, situados entre os 25 - 45 anos. A opção por essa faixa etária se deu por dois critérios. Em primeiro lugar, segundo se trata de um grupo que majoritariamente está inserido no mercado de trabalho e, em segundo lugar, esses sujeitos tendem a ser consumidores potenciais das quatro empresas cujos discursos também analisamos. Nessas entrevistas, pudemos indagar a esses consumidores tanto sobre o conceito de consumo consciente quanto acerca da percepção dos mesmos sobre a comunicação das quatro empresas estudadas no tocante às práticas de consumo consciente.

Como procedimento de análise, trabalhamos com a perspectiva dos Estudos Críticos do Discurso (ECD). Esses não constituem um método ou escola (VAN DIJK, 2003, p.144) e sim representam o domínio articulado de um conjunto de práticas acadêmicas na qual confluem saberes de diversas disciplinas das ciências sociais e humanas. Sendo assim, Van Dijk (2010, p.11) pondera que não há "um" método ou "um" só tipo de análise possível.

A opção pelos ECD se deu em base a três argumentos teórico-metodológicos. Em primeiro lugar, entendemos que é importante frisar que trabalharemos com discursos e, pelo enfoque teórico proposto, faz-se necessário entende-los como práticas sociais (FAIRCLOUGH, 2003), proposta angular dos ECD. Desse modo, os discursos analisados são indissociáveis do contexto social, político, econômico e cultural ao qual se relacionam. Em segundo lugar, optamos pelos ECD posto que esta perspectiva permite ao pesquisador construir o universo meta-teórico referencial com o qual trabalhará. Nesse sentido, utilizaremos os três paradigmas éticos e as definições de consumo consciente, descritos anteriormente, para analisar os discursos selecionados. Assim mesmo, em terceiro lugar, os ECD buscam não só analisar as estruturas 
discursivas em si mesmas como também defendem o estudo dessas em relação com as estruturas sociais. Para Van Dijk (2010), todos e quaisquer discursos são produzidos por grupos sociais que pretendem impor uma determinada estrutura discursiva na sociedade. Desse modo podemos assumir que os discursos construídos ambicionam impor certa estrutura discursiva para a construção de determinadas realidades sociais. Obviamente, trata-se de um processo potencial, de uma disputa pela construção dos sentidos, consciente ou inconscientemente.

Tendo isso em vista o objetivo do presente trabalho e ao optar por seguir os postulados dos ECD tomamos por base a noção de "macro-proposição", sugerido por Van Dijk (2003). A produção de qualquer discurso abarca uma sequência de proposições, enunciados, que trazem consigo parte do significado global do discurso e da anterior proposição. Sendo assim, extraímos uma macro-proposição de cada um dos discursos analisados, sejam os enunciados por organizações ou pelos consumidores entrevistados, com o intuído de estudar a estrutura discursiva do mesmo. Posto isso, relacionamos o mesmo com os modelos éticos construídos e com as definições de consumo consciente, descritas anteriormente.

A análise dos discursos organizacionais revelou uma adequação dos discursos das quatro empresas selecionadas com a proposta do Instituto Akatu para entender o conceito de consumo consciente. A Nestlé defende como consumo consciente aquele que "Faz bem", um consumo diferente do tradicional posto que o mesmo deve priorizar a qualidade de vida. Como eixo discursivo, opera com a noção de "criação de valores compartilhados". No entanto, os valores colocados em partilha são os valores da própria organização. Não há um espaço para a negociação dos mesmos. Por dogmáticos, se encaixam na "ética da convicção".

Seguindo esta mesma linha, a HP também propõe "valores partilhados" como eixo da sua construção sobre o consumo consciente. Contudo, a HP enfatiza aspectos ecológicos das práticas de consumo, principalmente no tocante à reciclagem de cartuchos de impressoras ou à coleta de componentes informáticos em desuso. No entanto, a empresa não estimula o reuso, fomentando assim a cultura de um consumo material perene porque para a mesma, consumo consciente é também "consumir diferente". Ainda que não seja cristalino, a HP situa a defesa de um consumo que seja responsável para com o meio ambiente, o que indicaria a sua relação com a ética da responsabilidade. No entanto, a organização não indica a possibilidade de aceitar postulados que sejam benéficos para com os outros (como o reuso de cartuchos de 
impressora) e, portanto, também defende a universalização dos seus valores, agindo em base a uma ética da convicção.

Para o Santander, o consumo consciente está atrelado diretamente à performance da organização em sustentabilidade. Sendo assim, o consumo consciente é uma meta que o banco pretende transmitir aos seus públicos. Explicitamente, o Santander propõe "cuidar do dinheiro visando um consumo mais consciente". Trata-se, com efeito, de uma visão paternalista segundo a qual o consumidor precisa buscar o consumo consciente como um fim nele mesmo, o que também guarda uma marcada relação com a ética da convicção.

O banco Itaú, por sua vez, segue uma linha similar à adotada pelo Santander. Contudo, toma como eixo discursivo de toda a sua comunicação institucional a noção de consumo consciente como um ethos, um estilo de vida que deve balizar os valores dos indivíduos. A convicção do Itaú também faz com que o consumo consciente seja entendido como um fim nele mesmo, um dogma que representa um valor positivo e, portanto, adequado para a sociedade.

As entrevistas com os consumidores revelaram uma aceitação mediada, negociada do conceito de consumo consciente. Exceto para um dos entrevistados, que argumentou que esse conceito se tratava apenas de uma estratégica empresarial para alienar os consumidores, os demais entrevistados atrelaram a ideia de necessidade à noção de consumo consciente, destacaram que o mesmo seria um contraponto ao consumismo, que pressupõe uma ação racional, meditada do consumidor e destacaram que se trata de uma responsabilidade inerente ao fato de ser consumidor. Alguns exemplos:

Consumo consciente para mim é toda ação de consumo tomada com certo raciocínio, levando em conta a necessidade daquele consumo, as origens do produto a ser consumido, as consequência da produção deste bem de consumo, da necessidade que eu tenho de compara uma coisa qualquer. (Entrevistado A).

Para mim, consumo consciente é comprar com consciência sobre os impactos sociais e ambientais sobre o produto adquirido. É também não cair no consumismo. (Entrevistado E).

Os entrevistados - 9 entre 10 - destacaram aspectos ecológicos implicados nas práticas de consumo consciente atrelando-os à ideia de que consumir conscientemente é também contrapô-lo ao consumismo ou adequar as suas práticas de consumo às 
necessidades. Assim mesmo, 9 dos 10 entrevistados relatam a preocupação para com os outros, revelando uma aproximação, no entender dos mesmos, da ideia de consumo consciente como próprio de uma ética da responsabilidade. A ambivalência teórica sobre se o consumo consciente é aquele que restringe a aquisição de bens ou é uma prática ecologicamente responsável também ficou patente nos discursos dos entrevistados.

Por fim, ainda que não menos importante é a recepção dos discursos das organizações estudadas por parte dos entrevistados. Espontaneamente, apenas o Itaú foi lembrado como uma organização que fomenta o consumo consciente. Nenhum dos entrevistados indicou conhecer os postulados das outras três organizações sobre consumo consciente. Curiosamente, todos revelaram serem consumidores de pelo menos três das organizações estudadas e, no entanto, 9 dos 10 entrevistados revelaram que não levaram em consideração os discursos dessas no momento em que se tornaram clientes das mesmas ainda que matizaram o fato de que acreditavam ser imprescindível que as mesmas mantivessem políticas/posturas sobre práticas de consumo consciente.

\section{CONSIDERAÇÕES}

O estudo das interfaces entre ética comunicação organizacional e consumo revela um espaço profícuo para a produção de conhecimentos relevantes, tanto para o campo acadêmico como também para a sociedade. Especificamente, as chamadas práticas de consumo consciente estão presentes na agenda de diversas organizações e guardam um conceito ambivalente, seja relacionado a ações ecológicas ou à adequação do consumo às necessidades. Ambas as propostas ensejam refletir sobre valores morais, quer para problematizar as responsabilidades ou convicções de organizações ou consumidores entorno aos papéis (roles) sociais de cada um.

As organizações estudadas, no entanto, não defendem o consumo consciente como aquele que restringe práticas. Seguindo a proposta disseminada pelo Instituto Akatu, predicam um consumo diferente, atrelando-o mais ao apelo ecológico. Como valor moral, para essas organizações o consumo consciente se relaciona a um dogma, uma convicção e deve ser um fim nele mesmo.

É interessante destacar o contraponto observado nas entrevistas realizadas. A quase totalidade dos consumidores entrevistados relacionou o termo consumo consciente com questões ambientais e também com a adequação das práticas de 
consumo com as suas necessidades, desembocando em uma ética das responsabilidades. Sendo assim, os mesmos assumiram o papel de agentes que devem ter em conta em seus atos as consequências dos mesmos para com os demais e, em especial, para com o Planeta.

Consumir, conforme defendem diversos autores trabalhados, é uma prática de partilha de significados. Ao consumir, estamos comunicando escolhas, preferencias, gostos dentro de uma lógica cultural que atribui valores às formas simbólicas (MILLER, 2007). Problematizar a ética nesse contexto permite entender como organizações e consumidores buscam comunicar à sociedade que práticas de consumo são virtuosas. Entender a moralidade que permeia estes discursos abre uma via para compreender que não existem valores absolutos e sim estratégias discursivas edificadas a partir da constatação do lugar de fala de cada ator social.

\section{REFERÊNCIAS}

AKATU. O Akatu. Consumo Consciente. Disponível em: http://www.akatu.org.br/ Institucional/OAkatu. Acessado em 17 de janeiro de 2013.

ALONSO, J. L. La era del consumo. 1ª . Reimp. Madri: Siglo XXI, 2006.

ARENDT, H. A condição humana. $10^{\text {a }}$ Ed. Rio de Janeiro: Forense Universitária, 2004.

BARBOSA, L. CAMPBELL, C. Cultura, consumo e identidade. Rio de Janeiro: Editora FGV, 2006.

BARROS FILHO, C. Ética e comunicação organizacional. São Paulo: Paulus, 2007.

MEUCCI, A. A vida que vale a pena ser vivida. Petrópolis: Vozes, 2010.

BARROS, Denise. COSTA, Alessandra. AYROSA, Eduardo. SAUERBRON, João Felipe. "The production and dissemination of conscious consumption discourse in Brazil”. In: Advances in consumer research, 2010, Vol.37, pp.757-758.

CAMPBELL, C. A ética romântica e o espírito do capitalismo. Rio de Janeiro: Rocco, 2008.

CAMPS, V. "La ética no es una colección de normas, es una sensibilidad". In: La Vanguardia, 04 de Fev. de 2012.

CHAUÍ, M. Convite à filosofia. 14ª . Ed. São Paulo: Ática, 2012. 
CONNEL, K. H. "Internal and external barriers to eco-conscious apparel acquisition". In: International Journal of Consumer Studies, Vol.34, 2010, pp.126-136.

CORTINA, A. Ética sem moral. São Paulo: Martins Fontes, 2010.

DOSSIE - Ética e Comunicação nas organizações. In: Organicom, v.5, n.8, 2008, p.48110.

ENRIQUEZ, E. “Os desafios éticos nas organizações modernas”. In: RAE - Revista de Administração de Empresas, v. 37, n.2, Abr./Jun. 1997, p.6-17.

ETIZIONI, A. "Voluntary simplicity characterization, select psychological implications, and societal consequences". In: Journal of Economic Psychology, Vol. 19, p. 619-643.

Palabra, 2007.

La dimensión moral: hacia una nueva economía. Madri: Ediciones

FAIRCLOUGH, N. Analysing discourse: textual analysis for social research. Londres: Routledge, 2003.

FREIRE FILHO, J. "Sonhos de grandeza: o gerenciamento da vida em busca da alta performance". In: FREIRE FILHO, J. COELHO, M.G. (Org.) A promoção do capital humano. Mídia, subjetividade e o novo espírito do capitalismo. Porto Alegre: Sulina, 2011.

KANT, I. Crítica da razão prática. São Paulo: Edições e Publicações Brasil, 2004.

Fundamentação da metafísica dos costumes e outros escritos. São Paulo: Martin Claret, 2002.

LOVISON, A. M. PETROLL, M. M. "Ética na publicidade e propaganda: a visão do executivo de agencias de comunicação do Rio Grande do sul". In: Cadernos EBAPE.BR, v. 9, n.2, junho, 2011, p.333-359.

MALDONADO, A. E. "Práxis teórico/metodológica na pesquisa em comunicação: fundamentos, trilhas e saberes". In: MALDONADO, A.E. (Org.) et al. Metodologias de pesquisa em comunicação: olhares, trilhas e processos. Porto Alegre: Sulina, 2006.

MARCONDES, D. Textos básicos de ética: de Platão a Foucault. Rio de Janeiro: Zahar, 2009.

MARINA, J.A. Ética para náufragos. 9ª Ed. Barcelona: Anagrama, 2011.

MILLER, D. "Consumo como cultura material”. In: Horizontes Antropológicos, ano 13, n.28, jul/dez 2007, p.33-63.

PEPPER, M. et al. "An examination of the values that motivate socially conscious and frugal consumer behaviours". IN: International Journal of Consumer Studies, Vol.33, 2009, pp.126-136. 
RICOEUR, P. Ética e moral. Covilhã: Universidade da Beira Interior, 2011. Disponível em: http://www.lusosofia.net/textos/ricoeur_paul_etica_e_moral_rpf1990.pdf. Acessado em 08 de agosto de 2013.

RIOS, T.A. "A presença da filosofia e da ética no contexto profissional”. In: Organicom, v.5, n.8, 2008, p.78-88.

ROCHA, R. M. CASAQUI, V. (Orgs.) Estéticas Midiáticas e narrativas do consumo. Porto Alegre: Sulinas, 2012.

ROUX, C. NANTEL, J. “Conscious consumption and its components". In: Advances in consumer research, 2010, Vol.10, pp.903-904.

SILVA, Maria das Graças e. ARAÚJO, Nailsa Maria Souza. SANTOS, Josiane Soares. "Consumo consciente: o ecocapitalismo como ideologia". In: Revista Katálysis, Jun 2012, vol.15, no.1, p.95-111.

SPONVILLE, A. C. Invitación a la filosofía. Barcelona: Paidós, 2002.

SROUR, R.H. "Por que empresas eticamente orientadas?" In: Organicom, v.5, n.8, 2008, p. 60-67.

Ética empresarial: posturas responsáveis nos negócios, na política e nas relações pessoais. Rio de Janeiro: Campus, 2000.

SZMIGIN, Isabelle. CARRIGAN, Marylyn. McEACHERN, Morven. "The conscious consumer: taking a flexible approach to ethical behavior". In: International Journal of Consumer Studies, Vol.33, 2009, p.224-231.

TASCHNER, G. B. "Dimensões políticas da cultura do consumo". In: Lua Nova, n. 42, p. 183-199, 1997.

VALLS, A. L. M. O que é ética. 30ª reimp. São Paulo: Brasiliense, 2012.

VAN DIJK, Teun A. "La multidisciplinariedad del análisis crítico del discurso: un alegato a favor de la diversidad". In: WODAK \& MEYER (Orgs.). Métodos de análisis crítico del discurso. Barcelona: Gedisa, 2003.

VAN DIJK, Teun A. Discurso e Poder. São Paulo: Contexto, 2010.

WEBER, M. La "objetividad" del conocimiento en la ciencia social y en la política social. Madri: Alianza Editorial, 2009.

WEBER, M. Ciência e Política: duas vocações. São Paulo: Cultrix, 2011. 
Original recebido em: 22/09/2013

Aceito para publicação em: Novembro de 2013

Luiz Peres-Neto

Docente e pesquisador permanente do Programa de Pós-Graduação stricto sensu em Comunicação e Práticas de Consumo (PPGCOM) da ESPM. 